\title{
Seguridade social na América Latina e financiamento da Atenção Primária de Saúde
}

Recebido: 28 jan 2019 Aceito: 10 fev 2019

Autor de correspondência: thereza.nusc@uefs.br

Conflito de interesses: Os autores declaram não haver nenhum interesse profissional ou pessoal que possa gerar conflito de interesses em relação a este manuscrito.
${ }^{(1)}$ Universidade Estadual de Feira de Santana - UEFS, Feira de Santana, BA, Brasil.

\section{Resumo}

A implementação da Atenção Primária de Saúde - APS na América Latina (AL) possui particularidades regionais diferentes do contexto europeu, cujos sistemas de saúde encontram-se mais próximos à universalidade, com financiamento público, abrangendo quase a totalidade da população e considerando uma ampla gama de serviços. Reformas recentes introduzidas nos sistemas de saúde europeus fortaleceram a APS enquanto coordenadora dos cuidados e porta de entrada preferencial. Ampliou-se o leque de prestações fornecidas e outorgou-se à APS maior controle sobre outros níveis de atenção; no entanto, os maiores sucessos aconteceram nos países financiados por impostos gerais, institucionalizados em sistemas nacionais de saúde, do que em aqueles cujo financiamento se dá por meio de seguros sociais compulsórios. Nos países da AL, coexistem vários subsistemas com modalidades de financiamento e asseguramento próprias, os que outorgam cobertura diferenciando segundo capacidade de pagamento, inserção no mercado formal de trabalho, ou pela presença de alguma doença. Encontram-se os seguros sociais destinados à população no mercado formal de trabalho, seguros focados nos grupos em situação de pobreza ou para a resolução de algum problema de saúde específico, a cobertura por parte das instituições públicas nacionais ou subnacionais, além de um sistema de seguros privados para as camadas de mais alta renda. Tal conformação dos arranjos da proteção compromete a consecução do valor da equidade e a eficiência no uso dos recursos, em uma região onde a precariedade dos empregos dificulta ainda mais esquemas afetivos de proteção social mediante contribuições sociais. Outra característica presente nos sistemas de saúde da América Latina é a fragmentação organizacional entre instituições públicas, da seguridade social e privada, a qual prejudica a coordenação em rede dos serviços e a integralidade da atenção. Ao mesmo tempo, os sistemas apresentam uma ampla participação do setor privado no financiamento e na prestação dos serviços, como consequência das reformas introduzidas nas décadas dos anos 1980 e 1990. Diferentemente dos países europeus, a APS vem sendo implementada enquanto porta de entrada dos serviços públicos apenas em alguns países (Brasil, Chile e Costa Rica), existindo também países que implementaram programas verticais destinados a problemas específicos de saúde (El Salvador, Nicarágua, Bolívia), além de sistemas de seguros de saúde onde a 
APS depende da iniciativa municipal (Colômbia e Argentina). As reformas aos sistemas de saúde da década dos anos 1980 e 1990 incentivaram a expansão de programas e políticas de saúde, alinhados com uma APS seletiva. Entretanto, na década dos anos 2000, após o ajuste estrutural, a região teve governos de esquerda ou centro-esquerda comprometidos com reformas em saúde em prol da universalidade e da consecução de uma atenção primária robusta. Diante desse panorama, o fortalecimento da APS constitui um dos principais desafios para os sistemas de saúde da região. Desde uma perspectiva ético-política, entende-se que uma APS abrangente conforma a base dos sistemas nacionais de saúde e é uma garantia da consecução do direito universal à saúde. Não obstante, os aspectos elencados antes conformam obstáculos que condicionam negativamente a consecução de uma APS robusta. Um primeiro elemento transversal aos países da região é a constatação de que as políticas nacionais sobre APS estão incorporando conteúdos baseados na concepção da APS abrangente presente na Declaração de Alma Ata, realçando a garantia da integralidade na atenção e a equidade em saúde; inclusive, em sete dos doze países a APS se concebe como a base dos sistemas universais de saúde; em casos como Bolívia, Equador e Venezuela a essas concepções foram acrescentadas a questão da interculturalidade em saúde. As mudanças no modelo de atenção, com foco na conformação de equipes multiprofissionais para trabalho comunal com famílias, territorialização das ações e institucionalização de instâncias de participação social, também são elementos compartilhados nas políticas dos diferentes países. Sobre as características relevantes da APS na região, o nível nacional é representado frequentemente pelo Ministério da Saúde, órgão encarregado da direção das políticas; exceções são Argentina, onde as províncias possuem grandes níveis de autonomia, e Colômbia, que não tem consolidado uma política nacional de atenção primária na legislação nacional. Quanto ao financiamento, usualmente a APS é financiada na mesma modalidade que o sistema de saúde e apenas no Brasil não existem aportes das contribuições sociais sobre a folha dos salários. Ao considerar só as fontes públicas, na maioria dos países a responsabilidade financeira é do nível nacional; entretanto, no Brasil e Chile os municípios fazem aportes destinados à APS; em Peru e Bolívia existem aportes dos seguros sociais focados na população pobre; e na Colômbia os serviços de primeiro nível recebem fundos do nível nacional, municipal e dos seguros contributivos e subsidiados. As transferências do nível central para órgãos subnacionais são feitas por meio de programas específicos (Argentina, Equador, Venezuela), através de cálculo per capita da população municipal (Chile e Brasil) ou por repasses diretos segundo orçamento geral do Ministério da Saúde (Paraguai, Uruguai e Suriname); além disso, na Bolívia e Peru as transferências per capita são feitas aos municípios, mas, devendo ser direcionadas aos seguros para problemas de saúde específicos que esses países implementaram. Por outro lado, a prestação é feita pelos municípios, nos casos do Chile, Colômbia e Brasil, ao tempo que instâncias subnacionais prestam serviços na Argentina, Equador e Bolívia, além de que o Ministério da Saúde 
também atua como prestador no Uruguai, Paraguai, Guiana e Venezuela. Em sínteses, os resultados da literatura mostram que governos de esquerda ou centro-esquerda da região, nos anos 2000, introduziram mudanças à política de saúde de atenção primária, tentando incorporar a conceptualização da APS abrangente presente na Declaração de Alma-Ata; porém, essas tentativas foram obstaculizadas pela herança de uma proteção social à saúde fortemente segmentada. Os mesmos trabalhos também sugerem uma vinculação entre sistemas universais de saúde e maiores sucessos na consecução de uma APS integral, na América do Sul, ao tempo que sistemas baseados em seguros, públicos e privados, com populações e cestas de serviços restritas, encaminham seus esforços para uma APS seletiva. Na incorporação da APS em sistemas baseados no asseguramento, geralmente esta se destina a populações sem capacidade de pagamento ou de mais baixas rendas. Nesses casos, os principais obstáculos são a inconsistência entre diretrizes da política de saúde e direcionalidade introduzida pelas instituições encarregadas dos fundos de asseguramento, além da pouca integração do financiamento para ações coletivas e individuais.

Descritores: Financiamento Governamental; Iniquidade Social; Saúde Pública. 